\title{
Motivação autônoma de estudantes de física: evidências de validade de uma escala
}

\author{
Luiz Clement \\ Universidade do Estado de Santa Catarina - SC \\ José Francisco Custódio \\ Universidade Federal de Santa Catarina - SC \\ Sueli Édi Rufini \\ Universidade Estadual de Londrina - PR \\ José de Pinho Alves Filho \\ Universidade Federal de Santa Catarina - SC
}

\begin{abstract}
Resumo
Sob a orientação da Teoria da Autodeterminação foi elaborado um instrumento para avaliar a motivação de estudantes do Ensino Médio para realizar atividades da disciplina de Física e buscaram-se evidências de sua validade. À pergunta inicial "Por que eu faço as atividades nas aulas de Física?" seguiu-se um conjunto de 55 afirmativas, em escala Likert de cinco pontos. A escala foi aplicada a uma amostra composta por 708 estudantes do Ensino Médio. Foram realizadas as seguintes análises estatísticas: análise fatorial, com extração dos componentes principais; análises de consistência interna; estatísticas descritivas e correlação de Pearson. Foram encontrados seis fatores representativos: Desmotivação $\alpha=0,89$; Regulação Externa - RP (Regras ou Punições) $\alpha=0,73$; Regulação Externa - RS (Recompensas Sociais) $\alpha=0,76$; Regulação Introjetada $\alpha=0,68$; Regulação Identificada $\alpha=0,91$ e Motivação Intrínseca $\alpha=0,93$, os quais explicam $51,74 \%$ da variabilidade dos dados. Os resultados indicaram que a escala é confiável e apta para ser utilizada em novas investigações.
\end{abstract}

Palavras-chave: Motivação, autodeterminação, ensino da física.

\section{Autonomous motivation of physics students: evidence of validity of a scale}

\begin{abstract}
Based on the Theory of Self-Determination we prepared an instrument to evaluate the motivation of high school students when developing activities of the Physics. We sought to evidence the scale validity, by asking an initial question: Why do I do the activities in the physics classes?." It was presented a set of 55 affirmatives, in a Likert scale with five-point. This scale was applied to a sample of 708 high school students. Were conducted the following statistical tests: factor analysis, with principal components extraction; analysis of internal consistency, descriptive statistics and the Pearson correlation. We found six representative factors: demotivation $\alpha=0.89$; External Regulation $-\mathrm{RP}$ (Rules or Punishment) $\alpha=0.73$; External Regulation - RS (Social Rewards) $\alpha=0.76$; Introjected Regulation $\alpha=0.68$; Identified Regulation $\alpha=0.91$ and Intrinsic Motivation $\alpha=0.93$, explaining $51.74 \%$ of data variability. The results indicate that we may trust the scale and we can use it in future research projects.
\end{abstract}

Keywords: Motivation, self determination, physics teaching.

\section{Motivación autónoma de estudiantes de física: evidencias de validez de una escala}

\section{Resumen}

Orientados por la Teoría de la Autodeterminación se diseñó un instrumento para evaluar la motivación de estudiantes de enseñanza de nivel secundario para realizar actividades de la disciplina de Física y se buscó evidencias de su validez. A la pregunta inicial "¿Por qué hago las actividades en las clases de Física?" le seguía un conjunto de 55 afirmativas en escala Likert de cinco puntos. La escala se administró a una muestra de 708 estudiantes de Enseñanza Secundaria. Se realizaron los siguientes análisis estadísticos: análisis factorial con extracción de los componentes principales; análisis de consistencia interna; estadísticas descriptivas y correlación de Pearson. Se encontraron seis factores representativos: Desmotivación $\alpha=0,89$; Regulación Externa - RC (Reglas o Castigos) $\alpha=0,73$; Regulación Externa - RS (Recompensas Sociales) $\alpha=0,76$; Regulación Introyectada $\alpha=0,68$; Regulación Identificada $\alpha=0,91$ y Motivación Intrínseca $\alpha=0,93$. Tales factores explican $51,74 \%$ de la variabilidad de los datos. Los resultados indicaron que la escala es fiable y apta para ser utilizada en nuevas investigaciones.

Palabras Clave: Motivación, autodeterminación; enseñanza de física. 


\section{Introdução}

No contexto escolar a motivação é apontada pelos professores como um elemento importante no processo de ensino-aprendizagem, embora ainda sejam escassos os estudos sobre essa temática (Martinelli \& Bartholomeu, 2007). As pesquisas sobre motivação, realizadas nos últimos anos, foram desenvolvidas com diferentes aportes teóricos, e sinalizaram que a motivação para aprender é de natureza multidimensional e se constitui em um objeto de pesquisa bastante complexo (Alsop, 2005; Bybee \& McCrae, 2011; Boruchovitch \& Bzuneck, 2010; Silvia, 2006). A complexidade relativa à motivação justifica, em parte, as distintas explicações dadas pelos professores ao descreverem o motivo de muitos de seus alunos não estarem interessados em suas aulas. Diante disso, a motivação (ou a falta de) para aprender se configura como um problema a ser enfrentado pelos professores no desenvolvimento de seu trabalho e demanda novos estudos para propiciar uma maior compreensão e indicar frentes de ações práticas no contexto escolar.

As pesquisas na área educacional, baseadas na Teoria da Autodeterminação, investigam a motivação extrínseca e intrínseca, inclusive mediante a proposição e validação de instrumentos (Black \& Deci, 2000; Broc, 2006; Deci e cols., 1981; Gottfried, Fleming, \& Gottfried, 2001; Guimarães \& Bzuneck, 2008; Harter, 1981; Lepper, Corpus, \& lyengar, 2005; Martinelli \& Bartholomeu, 2007; Neves \& Boruchovitch, 2006; Rufini, Bzuneck, \& Oliveira, 2011; Vallerand e cols., 1989). Outros estudos (Broc \& Gil, 2008; Stefanou e cols., 2004;) buscam relacionar os aspectos da motivação autônoma (formas autodeterminadas de motivação extrínseca e motivação intrínseca) com elementos importantes e inerentes ao processo de ensino-aprendizagem, tais como suportes organizacionais, procedimentais, cognitivos e afetivos. Estes trabalhos são conduzidos, em sua maioria, por pesquisadores oriundos do campo da Psicologia ou da área de Educação (Psicologia Educacional) focados em estudos sociocognitivos.

Nas publicações relativas aos trabalhos empíricos, alguns pesquisadores ressaltam a importância de novos estudos nessa área, tanto para fortalecer os aportes teóricos quanto para aprimorar os instrumentos utilizados para mapeamento do construto motivacional no campo da educação (Koh \& Frick, 2010; Roth e cols., 2007; Tsai e cols., 2008;). Estes trabalhos explicitam também a necessidade e importância de se realizarem pesquisas relacionadas a áreas especificas do saber, uma vez que o construto motivacional poderá variar entre as várias áreas do conhecimento (Boruchovitch \& Bzuneck, 2010).

Tomando-se como exemplo o ensino de Ciências, em geral, e da Física em particular, é significativa a reclamação e denúncia, por parte dos professores, de falta de interesse e motivação dos alunos para estudar e aprender Física (Ricardo, 2010, entre outros). Somando-se a isto, resultados atuais de pesquisas evidenciam baixa qualidade, ou mesmo o declínio da motivação para aprender ciências ao longo do processo de escolarização de jovens estudantes (Baram-
-Tsabari \& Yarden, 2005; Buccheri, Gürber, \& Brühwiler, 2011; Krapp \& Prenzel, 2011; Park, Khan, \& Petrina, 2009). Neste sentido, com base na Teoria da Autodeterminação, no presente estudo foi elaborada uma escala para medir a motivação dos estudantes para realizar as atividades didáticas nas aulas de Física do Ensino Médio e investigadas as evidências de validade do instrumento.

\section{Teoria da autodeterminação}

Na Teoria da Autodeterminação a leitura e discussão sobre a motivação estão baseadas na tese de que os seres humanos são ativos e propensos ao desenvolvimento autorregulável. Assim sendo, esta teoria prediz que o envolvimento dos indivíduos em atividades de aprendizagem pode ser analisado do ponto de vista de três necessidades psicológicas básicas, inerentes à vida humana: as necessidades de competência, de pertencimento e de autonomia (Reeve, 2006; Ryan \& Deci, 2000b). A necessidade de competência se refere à compreensão de como alcançar diferentes resultados internos e externos quanto à eficácia da execução das ações necessárias. A necessidade de pertencimento envolve as conexões seguras e satisfatórias com os outros em um meio social, e a de autonomia refere-se à autoiniciativa e autorregulação de suas ações (Deci e cols., 1991). Esse é também o entendimento de Neves e Boruchovitch (2006) ao afirmarem que o ser humano possui uma tendência motivacional natural, que é responsável pelo seu desenvolvimento cognitivo, social e afetivo.

A Teoria de Autodeterminação e outras teorias sociocognitivas procuraram evidenciar duas formas de motivação, a intrínseca e a extrínseca (Deci e cols., 1991; Harter, 1981; Lepper, Corpus \& lyengar, 2005; Ryan \& Deci, 2000a). A motivação intrínseca se caracteriza pelo interesse e satisfação pela atividade em si, ou seja, o envolvimento é livre e voluntário e não necessita de recompensas ou punições; já a motivação extrínseca é descritiva de ações e atividades realizadas em resposta a algo externo, ou seja, está ligada à obtenção de recompensas, reconhecimento, obediência a ordens, ou ainda, a escapar de sanções e punições. É importante destacar que inicialmente, nas primeiras pesquisas sobre motivação intrínseca e motivação extrínseca, concebia-se uma relação antagônica entre estas duas formas de motivação (Deci, 1971). Nessa perspectiva, considerava-se que os comportamentos extrinsecamente motivados não possuíam condicionante de autodeterminação, sendo este aspecto válido apenas para comportamentos motivados intrinsecamente.

O refinamento teórico, decorrente dos resultados de pesquisas empíricas, conduziu os proponentes da Teoria da Autodeterminação a considerarem distintos níveis de regulação do comportamento intencional, variando em função do grau de autodeterminação percebida (Deci e cols., 1991; Deci \& Ryan, 1985; Vallerand e cols., 1989;). Estes diferentes níveis de regulação acabaram constituindo um continuum da regulação comportamental associada à mo- 
tivação humana. Assim sendo, foram identificados quatro tipos qualitativamente diferenciados de motivação extrínseca: a motivação externa, a introjetada, a identificada e a integrada. A argumentação central para o estabelecimento destes diferentes níveis de regulação comportamental está baseada no conceito de internalização. Por internalização entende-se um processo mediante o qual as pessoas transformam regulações por contingências externas em regulações por processos internos (Bzuneck \& Guimarães, 2010; Deci e cols., 1991). As pesquisas mais recentes evidenciaram com maior clareza e detalhe a existência do continuum da regulação do comportamento (figura 1), constituindo uma taxonomia da motivação humana (Niemiec \& Ryan, 2009; Reeve, 2006; Ryan \& Deci, 2000a, 2000b).

A desmotivação, localizada na extremidade esquerda, caracteriza-se pela ausência de intenção ou motivação para agir. O primeiro nível da motivação extrínseca é identificado como regulação externa. Neste nível motivacional são compreendidos os comportamentos adotados pelas pessoas em função de controladores externos (não determinados pelo self) como, por exemplo, buscar recompensas ou evitar ameaças ou punições. No segundo nível da motivação extrínseca temos os comportamentos que já assumem certo grau de internalização, ou seja, há uma regulação por introjeção; portanto, na regulação introjetada a pessoa age em função de pressões que ela própria se impõe - por exemplo, cumpre a atividade para evitar sentimentos de culpa ou de ansiedade, ou mesmo para não afetar sua autoestima. De acordo com Deci e cols. (1991) “... apesar da regulação introjetada ser interna à pessoa, ela se assemelha muito mais ao controle externo do que com as formas autodeterminadas de regulação, pois envolve a coerção ou a sedução e não implica numa verdadeira escolha" (p. 329). Assim, estes dois primeiros estados da motivação extrínseca são comportamentos não autodeterminados, mas formas controladas de motivação, seja por controladores externos (regulação externa) ou por controladores internos (regulação introjetada). A regulação identificada já se caracteriza como uma forma mais autônoma de motivação extrínseca. Neste tipo de regulação a pessoa acaba valorizando determinado comportamento e com ele se identificando, de forma a atribuir-lhe uma importância pessoal e, consequentemente, tomando o processo de regulação para si próprio. Dessa forma, o comportamento é tido como de relativa autodeterminação, uma vez que a pessoa age de bom grado, porque os reguladores externos estão alinhados ou são passíveis de indentificação com os valores ou demandas pessoais. Desse modo, a pessoa age por identificação, e não em função de cobranças ou pressões externas. De acordo com Bzuneck \& Guimarães (2010), um bom exemplo acaba sendo aquele aluno que tem como propósito tornar-se escritor e, em função disso, valoriza e toma para si as tarefas de fazer leituras.

O nível mais autodeterminado de motivação extrínseca é a regulação integrada. Neste nível motivacional as regulações são integralmente identificadas e assimiladas ao seu self. Diante disso, ocorrerá uma congruência entre as regulações assimiladas e os valores, necessidades, metas e identidades já anteriormente consolidadas dentro do indivíduo. A regulação integrada está muito próxima da motivação intrínseca (alocada no ponto extremo à direita do continuum), já que ambas possuem um lócus de causalidade totalmente interno. Não obstante, a motivação intrínseca é caracterizada pelo interesse pela atividade em si, sem haver a necessidade de atingir alguma meta, mesmo que seja de importância pessoal, mediante o desenvolvimento da tarefa. No caso da motivação extrínseca por regulação integrada, mesmo sendo o nível mais autônomo, para a regulação ainda há dependência em relação a aspectos externos. Em síntese, são considerados como tipos controlados a motivação extrínseca por regulação externa e introjetada e, em contrapartida, como tipos autônomos, a motivação extrínseca por regulação identificada e integrada, além da motivação intrínseca, tipo mais autodeterminado de motivação.

Esta taxonomia da motivação humana se torna um elemento teórico valioso para as pesquisas relativas à motivação escolar. Os diferentes tipos de regulação poderão

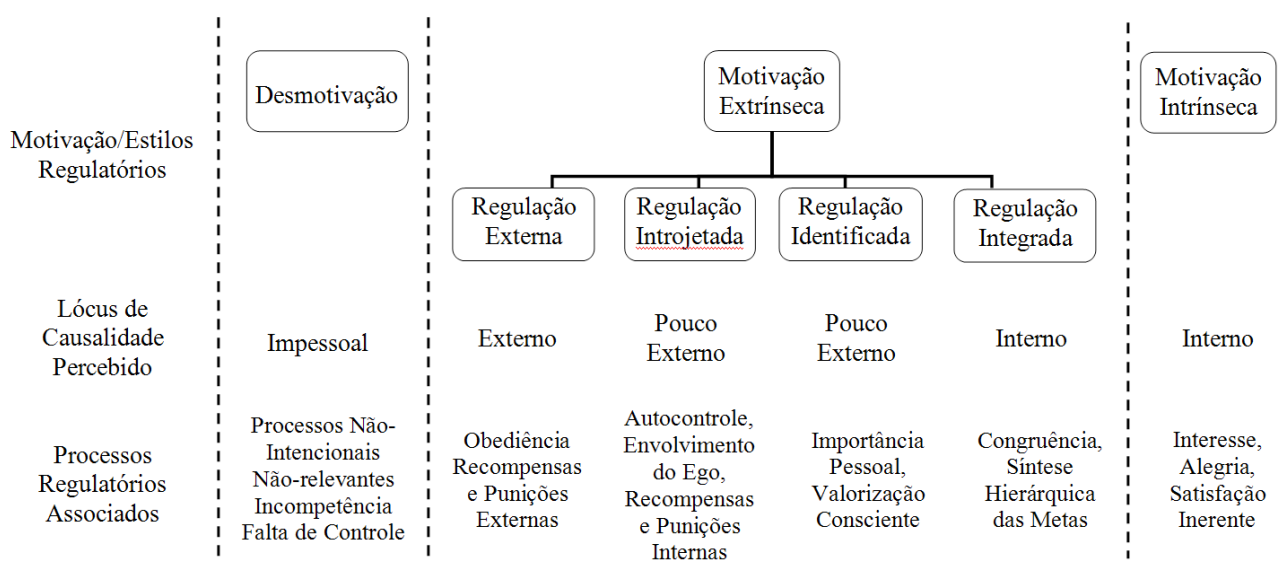

Figura 1: Continuum da regulação do comportamento - taxonomia da motivação humana, conforme Ryan \& Deci (2000a; 2000b) 
oferecer boas referências para a determinação dos níveis de internalização alcançados em uma dada situação; portanto, um instrumento que consiga avaliar a motivação de estudantes diante das atividades desenvolvidas em sala de aula possibilitará, ao professor ou ao pesquisador, avaliar e emitir conclusões sobre a relação entre níveis de autorregulação e interesse, envolvimento e esforço dos alunos nas atividades.

\section{Método}

\section{Instrumento}

Os itens que compuseram a escala de avaliação da motivação para realizar atividades da disciplina de Física (Escala de Motivação: Atividades Didáticas de Física - EMADF) foram elaborados com base na revisão da literatura específica (Broc, 2006; Deci e cols., 1981; Harter, 1981; Gottfried e cols., 2001; Guimarães \& Bzuneck, 2008; Lepper e cols., 2005; Matinelli \& Bartholomeu, 2007; Neves \& Boruchovitch, 2006; Rufini e cols., 2011; Vallerand e cols., 1989). Uma versão preliminar da escala continha uma pergunta inicial e 55 afirmativas, em escala Likert de cinco pontos.

Para eliminar interpretações dúbias das afirmativas e aproximá-las da linguagem dos respondentes, foi realizada a validação teórica e semântica (Pasqualim, 1997) da escala por intermédio de análises e discussões de especialistas (três pesquisadores) e de estudantes do Ensino Médio (possíveis respondentes) não diretamente envolvidos com esta pesquisa. Cabia aos especialistas qualificar as afirmativas de acordo com o continuum proposto pela Teoria da Autodeterminação (Ryan \& Deci, 2000a, 2000b) e deixá-las estruturadas de forma a permitirem uma fácil compreensão para os estudantes do Ensino Médio. Para o ajuste semântico final, foi realizada uma análise com um grupo de cinco estudantes da segunda série do Ensino Médio. Para eles foi apresentado o questionamento inicial (Por que eu faço as atividades nas aulas de Física?), e as afirmativas foram apresentadas em duas estruturas diferentes, quais sejam: a) contendo somente a razão (ex.: Porque acho legal aprender com elas); ou b) contendo a ação + a razão (ex.: Faço as atividades porque acho legal aprender com elas). Quanto à estrutura das afirmativas, os alunos apresentaram uma compreensão significativamente melhor quando estas foram redigidas de acordo com a forma $b$, ou seja, quando a afirmativa apresenta em sua redação, além da razão, também a ação (faço ou não faço a atividade). Além disso, foi necessário o ajuste na redação de duas afirmativas de maneira a deixá-las compreensíveis para os estudantes.

A versão final da escala contém o questionamento inicial "Por que eu faço as atividades nas aulas de Física?", seguido de um conjunto de 55 afirmativas, em escala Likert de cinco pontos ( 1 a 5 ), representando o continuum proposto pela teoria da autodeterminação (Ryan \& Deci, 2000a, 2000b). Não foram incluídos itens para avaliar a motivação extrínseca por regulação integrada, uma vez que a diferença entre este nível e o nível de motivação intrínseca é bastante tênue, dificultando muito a elaboração precisa das afirmativas de modo a captarem esta sutil diferença (Guimarães \& Bzuneck, 2008; Rufini e cols., 2011).

\section{Participantes}

Ao todo, participaram desta pesquisa 715 estudantes do Ensino Médio, oriundos de escolas públicas das cidades de Joinville/SC e Florianópolis/SC. Os estudantes responderam ao questionário de escala Likert e, após uma triagem, 708 questionários puderam ser utilizados para tabulação e análise dos dados. Sete questionários foram excluídos por não terem sido respondidos na íntegra ou pelo fato de todos os itens terem sido respondidos sob um mesmo valor da escala Likert. Do total de estudantes, correspondentes aos 708 questionários válidos, 322 (45,48\%) são do gênero masculino e 386 (54,52\%) são do gênero feminino; 288 $(40,68 \%)$ da primeira série, $210(29,66 \%)$ da segunda série e $210(29,66 \%)$ da terceira série do Ensino Médio. A média de idade destes estudantes era de 16,40 anos.

\section{Procedimento de coleta de dados}

Para a validação desta escala de medida de motivação foram prestados aos participantes todos os cuidados e respaldos previstos pela Resolução 196/96 do Conselho Nacional de Saúde e documentos complementares. Todas as instituições escolares autorizaram, via declaração escrita pela direção, a aplicação do questionário aos estudantes da escola, desde que se respeitasse a livre opção por participar. Além disso, antes de os estudantes responderem ao questionário foi lhes entregue o Termo de Consentimento Livre e Esclarecido, mediante o qual buscavam junto aos seus pais autorização para participar da pesquisa. O questionário foi aplicado sempre durante o horário da aula, na presença de um professor efetivo da escola. Os estudantes levaram, em média, 40 minutos para responder ao questionário. Vale ressaltar ainda que, com base no acompanhamento do processo de aplicação dos questionários, verificou-se que os alunos não apresentavam dificuldades em compreender os itens e a forma de atribuir o grau de veracidade a cada uma das afirmativas.

\section{Procedimento de análise de dados}

Os dados foram codificados e transportados para o programa STAT (Programa Statistica versão 8.0, da StatSoft Company) para as análises previstas. A análise fatorial com extração dos componentes principais e com rotação varimax foi utilizada para avaliar a dependência do conjunto de variáveis manifestas em relação a um número menor de variáveis latentes ou fatores (Kline, 1994); ou seja, por esta análise buscou-se determinar o número de fatores existentes para o 
conjunto de dados. Na sequência foram realizadas a análise de consistência interna (alfa de Cronbach), a análise estatística descritiva (médias e desvios padrão) e a correlação de Pearson.

\section{Resultados}

A partir da análise fatorial encontramos dez fatores com autovalor maior do que 1 , os quais explicaram $59,86 \%$ da variabilidade dos dados, conforme mostra a tabela 1.

Para auxiliar na decisão acerca da manutenção dos fatores, foi realizado o scree test, extraindo-se o gráfico dos autovalores, conforme a figura 2 .

Em face da coerência teórica dos itens e do gráfico de sedimentação (autovalores) apresentado na figura 2, foram considerados os seis fatores, para compor a escala. Adicionalmente, para que um item fosse considerado componente de um fator, estabeleceu-se como critério a carga fatorial (que deve ser igual ou superior a 0,30 ), a coerência

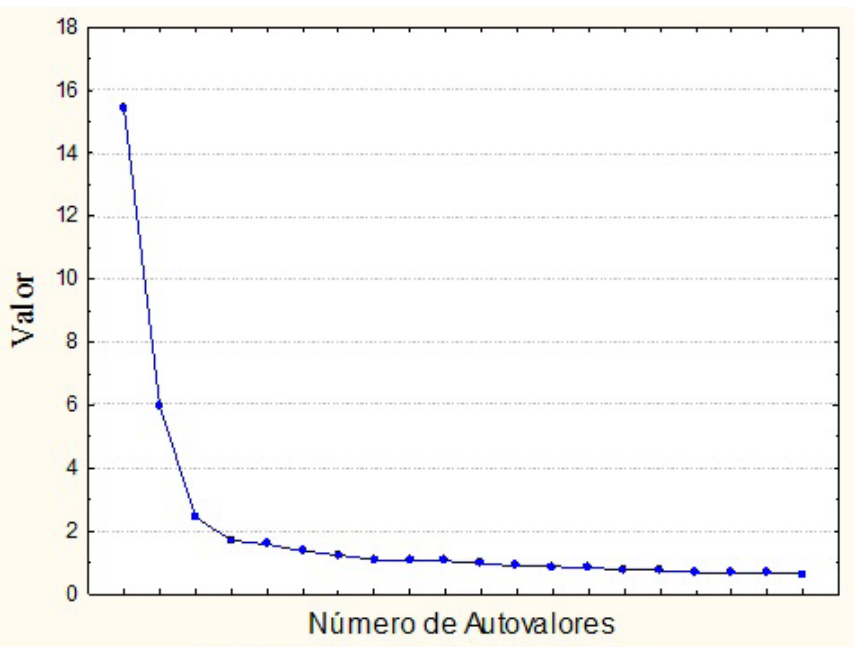

Figura 2. Diagrama de autovalores

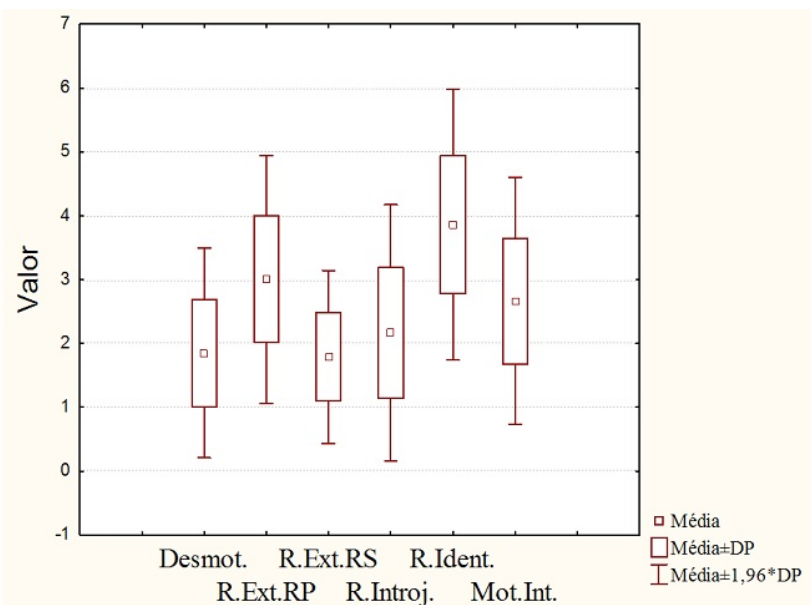

Figura 3. Box \& Whisker Plot - média e desvio padrão para cada variável da qualidade motivacional $(\mathrm{N}=708)$. teórica e a consistência interna dos itens medida pelo alfa de Cronbach. Diante disso, cinco itens da escala original foram excluídos.

No Fator 1 foi excluído, por razões teóricas, o item 38

(Faço as atividades porque o professor me estimula a fazer). Este item foi originalmente elaborado para avaliar a motivação extrínseca por regulação introjetada, porém se agrupou com itens de motivação intrínseca. Em relação ao Fator 2 , também por razões teóricas, foram excluídos os itens 11 (Faço as atividades para não desapontar meus pais) e 41 (Para deixar o professor satisfeito comigo, acabo fazendo as atividades). Originalmente concebidos para avaliar a motivação extrínseca por regulação introjetada, os itens se agruparam a outros itens representativos de motivação extrínseca por regulação externa, mais precisamente àqueles destinados a medir comportamentos motivados pela obtenção de recompensas sociais. O item 20 (O professor me obriga, aí acabo fazendo as atividades), agrupado ao Fator 3, também foi excluído por razões teóricas, uma vez que foi elaborado para avaliação da motivação extrínseca por regulação externa e se agrupou com itens de desmotivação. O quinto item eliminado foi o 04 (Quando vale nota, eu acabo fazendo as atividades), para melhorar o valor do alfa de Cronbach do Fator 4. Assim sendo, a escala final ficou com 50 itens, distribuídos em seis fatores, conforme mostra a tabela 2 .

Como os itens foram agrupados em torno dos seis fatores, com base na Teoria da Autodeterminação, foi possível nomeá-los da seguinte forma: Fator 1 - Motivação intrínseca, Fator 2 - Regulação externa - RS (Recompensas sociais), Fator 3 - Desmotivação, Fator 4 - Regulação Externa - RP (Regras ou Punições), Fator 5 - Regulação introjetada, e Fator 6 - Regulação identificada. Vale ressaltar que três dos itens inicialmente considerados para a avaliação da motivação extrínseca por regulação introjetada se agruparam nas subescalas Regulação externa, razão pela qual foram excluídos; Por isso a subescala Regulação introjetada permaneceu com apenas três itens. Além disso, destaca-se a separação dos itens propostos inicialmente para avaliação da motivação extrínseca por regulação externa em dois fatores: Regulação externa - RP e Regulação externa - RS. Este aspecto evidencia que os estudantes perceberam de formas diferentes os motivadores externos, subordinados a regras ou punições, e os elementos motivacionais, que buscam recompensas sociais (valorização ou reconhecimento). Os demais itens se agruparam conforme a previsão teórica inicial.

Os índices de consistência interna entre os itens de cada subescala, medidos pelo alfa de Cronbach, foram bons, ficando apenas um deles abaixo de 0,70, conforme segue: Desmotivação $\alpha=0,89$; Regulação externa - RP $\alpha=0,73$; Regulação externa - RS $\alpha=0,76$; Regulação introjetada $\alpha=0,68$; Regulação identificada $\alpha=0,91$ e Motivação intrínseca $\alpha=0,93$.

A figura 3 mostra as médias e desvios padrão, obtidos mediante uma análise de estatística descritiva, para o valor da resposta atribuído pelos estudantes a cada um dos itens que compõem as subescalas da qualidade motivacional. 
Tabela 1. Extração dos componentes principais com autovalor maior do que 1.

\begin{tabular}{ccccc}
\hline Fator & Autovalor & \% Variância & Autovalor Acumulado & \% Variância Acumulada \\
\hline 1 & 15,39 & 27,97 & 15,38 & 27,97 \\
2 & 5,96 & 10,83 & 21,34 & 38,80 \\
3 & 2,45 & 4,45 & 23,79 & 43,25 \\
4 & 1,71 & 3,11 & 25,50 & 46,37 \\
5 & 1,58 & 2,88 & 27,09 & 49,25 \\
6 & 1,37 & 2,50 & 28,46 & 51,74 \\
7 & 1,24 & 2,25 & 29,70 & 53,99 \\
8 & 1,10 & 2,00 & 30,80 & 56,00 \\
9 & 1,07 & 1,95 & 31,87 & 57,94 \\
10 & 1,05 & 1,92 & 32,92 & 59,86 \\
\hline
\end{tabular}

Pode-se observar que as duas maiores médias foram obtidas pelos participantes na avaliação da motivação extrínseca por Regulação identificada e por Regulação externa - RP; no entanto a Regulação dentificada já é um nível motivacional mais próximo da motivação intrínseca e, diferentemente da Regulação externa - $R P$, já possui um lócus de causalidade percebido como um pouco interno, o que quer dizer que já há processos regulatórios baseados em valorização consciente e importância pessoal.

Para aprofundar a análise das subescalas e obter maiores detalhes sobre a possibilidade de coexistência de estados motivacionais, possível em um pressuposto de continuum motivacional, foram levantadas as correlações de Pearson entre as médias dos escores calculados para os participantes, nas diferentes subescalas (tabela 3 ).

Pela tabela 3 constata-se que há correlações positivas e negativas entre os diferentes tipos de motivação. Conforme previsto teoricamente, foram encontradas correlações negativas entre os tipos de motivação alocados nos extremos do continuum e correlações positivas entre os tipos proximamente localizados.

\section{Discussão}

A presente pesquisa teve como suporte inicial os resultados obtidos por outras investigações, principalmente aquelas destinadas à elaboração e validação de escalas de medida de motivação em contexto escolar e apoiadas na Teoria da Autodeterminação. Destas foi possível retirar e adaptar uma série de itens para compor a EMADF. Além do mais, com base nos resultados destes estudos, ficou evidenciada uma lacuna quanto à proposição de escalas de medida da motivação para áreas especificas do conhecimento. Neste sentido, a elaboração e o levantamento de evidências de validade da EMADF contribuem diretamente com a área de conhecimentos, uma vez que, estão destinados à avaliação da motivação dos estudantes para realizarem atividades didáticas nas aulas de Física.

A análise fatorial exploratória revelou que a escala apresenta boas propriedades psicométricas, garantindo a validade da escala diante dos pressupostos teóricos. Os seis fatores considerados a partir dos resultados da análise respondem por $51,74 \%$ da variabilidade total dos dados. Os índices de consistência interna dos itens de cada fator, medidos pelo alfa de Cronbach, foram significativos, atribuindo confiança e credibilidade à escala; no entanto, em uma avaliação mais rígida, poder-se-ia buscar uma melhora nos índices das subescalas de Regulação externa $(0,73$ e $0,76)$ e Regulação introjetada $(0,68)$. Acredita-se que isso poderia ser atingido com a elaboração de novos itens que pudessem vir a se agrupar a estes fatores, possibilitando também, no caso da Regulação introjetada, a obtenção de uma subescala com maior número de itens; já nas outras três subescalas os índices podem ser considerados altos, ficando entre 0,89 e 0,93.

Os resultados obtidos pela análise de correlações entre as subescalas (tabela 3 ) confirmaram e fortaleceram nossa hipótese teórica de existência de um continuum de autodeterminação da motivação. Para confirmar a existência deste continuum da regulação do comportamento - que começa um estado de desmotivação, passa pela motivação extrínseca (diferentes níveis de regulação) e chega à motivação intrínseca) - as correlações entre as subescalas adjacentes deveriam ser positivas e as correlações entre as subescalas dos extremos opostos deveriam ser negativas. Os resultados, sintetizados na tabela 5 , revelaram correlações positivas entre Desmotivação e as duas subescalas de 
Tabela 2. Distribuição dos itens por fator com a respectiva carga fatorial

\begin{tabular}{|c|c|c|c|c|c|c|}
\hline \multirow{2}{*}{ Itens } & \multicolumn{6}{|c|}{ Fatores } \\
\hline & 1 & 2 & 3 & 4 & 5 & 6 \\
\hline 09. Eu me divirto fazendo as atividades. & 0,60 & & & & & \\
\hline 16. Acho as atividades interessantes, por isso as faço. & 0,70 & & & & & \\
\hline 19. Faço as atividades porque é prazeroso aprender com elas. & 0,72 & & & & & \\
\hline 23. Eu me envolvo nas atividades, por isso sempre procuro fazê-las. & 0,70 & & & & & \\
\hline 27. Faço as atividades pois o esforço exigido me gera satisfação. & 0,59 & & & & & \\
\hline 31. Faço as atividades porque acho legal aprender com elas. & 0,75 & & & & & \\
\hline $\begin{array}{l}\text { 33. Faço as atividades porque assim tenho a oportunidade de } \\
\text { satisfazer a minha própria curiosidade. }\end{array}$ & 0,72 & & & & & \\
\hline 36. Faço porque eu aprecio as atividades de Física. & 0,77 & & & & & \\
\hline 42. Por ser agradável parar para pensar ao fazer as atividades é que as faço. & 0,72 & & & & & \\
\hline 45. Faço as atividades porque isso me deixa feliz. & 0,78 & & & & & \\
\hline 51. Faço porque eu gosto de fazer bem as atividades. & 0,68 & & & & & \\
\hline 55. Porque me sinto bem fazendo as atividades é que as faço. & 0,72 & & & & & \\
\hline
\end{tabular}

6. Faço as atividades para receber os elogios do professor.

17. Quero que o professor pense que eu sou um bom estudante, por isso faço as atividades.

21. Faço porque quero que meus colegas pensem que sou inteligente.

26. Sou recompensado por meus pais, por isso faço as atividades.

30. Para impressionar meus colegas eu acabo fazendo as atividades.

40. Faço as atividades para meus colegas não me chamarem de burro.

46. Meus pais sempre dizem para eu fazer as atividades e aí acabo fazendo.

52. Só faço as atividades porque meus colegas fazem.

0,32

03. Não gosto das atividades de Física, por isso não as faço.

07. Não tenho interesse por Física, o que me leva a não fazer quase nada nas aulas.

10. Não sei, acho que não tem nada para fazer nas aulas de Física.

13. As atividades de Física não são importantes para mim, por isso não as faço.

15. Sinceramente, não tenho nenhuma vontade de fazer as atividades de Física. 
22. Não faço as atividades de Física porque não vejo utilidade neste conhecimento.

25. Vou nas aulas de Física para responder a chamada, mas não faço nada.

28. Acho uma perda de tempo fazer as atividades nas aulas de Física.

35. De verdade, não vejo se fará diferença para mim se eu fizer ou não as atividades.

39. Tenho preguiça de fazer as atividades de Física, por isso não as faço.

34. Faço as atividades para não ser mandado para a direção ou orientação pedagógica.

37. Se não fosse regra, eu não faria as atividades.

48. Faço porque assim evito problemas ou punições na escola.

50. Para não ficar com uma nota baixa, acabo fazendo as atividades.

2. Faço porque eu vou me sentir mal comigo mesmo se eu não fizer.

24. Eu me envergonharei de mim mesmo se eu não fizer as atividades.

54. Faço as atividades porque me sinto angustiado se eu não fizer.

0,61

01. Procuro fazer as atividades porque elas me ajudam a detectar e superar minhas dúvidas.

05. Faço as atividades porque sinto que é uma boa maneira de melhorar minha compreensão dos assuntos abordados nesta disciplina.

08. Faço as atividades para constatar se estou certo ou errado.

12. Para o meu futuro será fundamental que eu faça as atividades.

14. Faço as atividades porque eu quero aprender coisas novas.

18. Faço as atividades porque assim aprendo cada vez mais.

29. As atividades me ajudarão a trilhar o caminho para ser alguém na vida, por isso as faço.

47. Acredito que somente fazendo as atividades é que se aprende, por isso sempre as faço. 
Tabela 3. Correlação de Pearson entre os escores médios nas variáveis da qualidade da motivação $(\mathrm{N}=708)$

\begin{tabular}{lcccccc}
\hline Variáveis & Desmotivação & $\begin{array}{c}\text { Reg. Externa } \\
- \text { RP }\end{array}$ & $\begin{array}{c}\text { Reg. Externa } \\
-\mathrm{RS}\end{array}$ & $\begin{array}{c}\text { Reg. } \\
\text { Introjetada }\end{array}$ & $\begin{array}{c}\text { Reg. } \\
\text { Identificada }\end{array}$ & $\begin{array}{c}\text { Motivação } \\
\text { Intrínseca }\end{array}$ \\
\hline Desmotivação & 1,00 & $0,41^{* * *}$ & $0,14^{* * *}$ & $-0,19^{* * *}$ & $-0,67^{* * *}$ & $-0,57^{* * *}$ \\
Reg. Externa - RP & & 1,00 & $0,34^{* * *}$ & $0,08^{*}$ & $-0,25^{* * *}$ & $-0,25^{* * *}$ \\
Reg. Externa - RS & & 1,00 & $0,37^{* * *}$ & $0,15^{* * *}$ & $0,25^{* * *}$ \\
Reg. Introjetada & & & 1,00 & $0,35^{* * *}$ & $0,44^{* * *}$ \\
Reg. Identificada & & & & 1,00 & $0,80^{* * *}$ \\
Motiv. Intrínseca & & & & & 1,00
\end{tabular}

Nível de significância (p): * $p<0,05 ;{ }^{* *} p<0,01 ;{ }^{* * *} p<0,001$.

Regulação externa, bem como uma correlação positiva, em valor maior, entre Motivação intrínseca e Regulação identificada. A forte correlação positiva existente entre Motivação intrínseca e Regulação identificada é justificada pelo fato de o lócus de causalidade percebido ter uma dimensão interna (total ou parcial) em ambos os estados motivacionais; ou seja, a regulação identificada, embora pertença à categoria Motivação extrínseca, possui um alto grau de regulação autodeterminada, essência da motivação intrínseca.

As correlações negativas se evidenciaram entre os estados motivacionais dos extremos opostos. As subescalas Motivação intrínseca e Regulação identificada apresentaram uma forte correlação negativa com Desmotivação e uma correlação negativa (com valores mais baixos) com a Regulação externa - RP; já a Regulação introjetada, localizada na parte intermediária do continuum, revelou uma correlação negativa com e correlações positivas (com valores não muito expressívos) com as demais subescalas. Isso é justificável, pois a Regulação introjetada é de fato uma subescala intermediária, que possui um lócus de causalidade percebido que já não é mais externo em sua totalidade, ou seja, os processos regulatórios relevantes do comportamento são ditados sobremaneira por recompensas e punições internas (orgulho, autoestima, vergonha, culpa). Assim os resultados obtidos pela análise de correlações proporcionaram mais um argumento favorável à validade da EMADF e reforçam sua conformidade com outros estudos de validação de escalas para medir a motivação de estudantes (Guimarães \& Bzuneck, 2008; Rufini e cols., 2011; Vallerand e cols., 1989).

Feita a avaliação, a escala permaneceu com um número total de 50 itens. Este conjunto grande de itens, por um lado permite uma ampla avaliação da motivação dos estudantes para fazer as atividades nas aulas de Física e, por outro, pode não ser interessante, pois demandará um maior tempo para aplicação e análise. Diante disso, sugerimos uma escala reduzida que poderia ser usada para outros fins além da pesquisa. Uma escala menor permitirá a realização de medidas mais rápidas, por exemplo, por um professor interessado em conhecer a qualidade motivacional de seus alunos para trabalhar pelo desenvolvimento de uma motivação mais autodeterminada. Para esta escala reduzida propomos os seguintes itens (números dos itens com referência à tabela 2): Desmotivação - 7, 13, 15, 22, 28 ( $\alpha=0,82)$; Regulação externa - RP - 32, 34, 37, 48, 50 ( $\alpha=0,73)$; Regulação externa - RS - 6, 17, 26, 30, 40 ( $\alpha=0,67)$; Regulação introjetada 2, 24, 54 ( $\alpha=0,68)$; Regulação identificada - 1, 5, 12, 18, 43 $(\alpha=0,82)$ e Motivação intrínseca - 19, 31, 36, 45, 55 ( $\alpha=0,87)$. Para a versão reduzida da escala, os valores dos índices de consistência interna $(\alpha)$ dos itens de cada subescala são um pouco menores que aqueles da escala completa, porém são aceitáveis e garantem a validade e confiabilidade.

\section{Considerações finais}

Avaliar a motivação de estudantes no contexto escolar é uma tarefa complexa. Por esta razão a validação de instrumentos elaborados com respaldo teórico consistente tem um papel importante para o avanço dos estudos nesta temática. Com instrumentos de coleta de informações, como é o caso da escala ora descrita, torna-se possível conhecer e compreender características importantes dos diferentes níveis de regulação do comportamento dos estudantes para efetuarem as atividades nas aulas. A partir do conhecimento destes dados será possível elaborar proposições didático-pedagógicas efetivas para a promoção da motivação autônoma em sala de aula.

Instrumentos brasileiros elaborados para medida da motivação, baseados na Teoria da Autodeterminação, ainda são escassos, principalmente os referentes a uma área específica do conhecimento. Diante disso, a EMADF, na sua versão completa ou mesmo reduzida, apresenta-se como uma alternativa importante para o estudo da motivação no contexto escolar, especialmente para a aprendizagem 
da Física. Uma compreensão mais clara e precisa sobre os aspectos motivacionais, quiçá sobre sua relação com a aprendizagem da Física, poderá certamente contribuir para solucionar alguns dos problemas enfrentados pelos professores em suas aulas.

Considera-se pertinente a utilização da EMADF como instrumento em pesquisas sobre o estudo da motivação para aprendizagem da Física, aliada a outros instrumentos ou formas de coleta de dados (observações, videogravações, entrevistas, entre outros). Isto se justifica porque se trata de um instrumento que coleta informações de forma autodeclarativa, não obstante as limitações relativas a esse tipo de levantamento de informações. Além disso, ressalta-se uma fragilidade da EMADF localizada na subescala Regulação introjetada, que possui apenas três itens e um baixo índice de consistência interna dos itens $(0,68)$, medida pelo alfa de Cronbach. Este aspecto poderá ser superado com a realização de novos estudos que se proponham a aprimorar a escala aqui apresentada.

Por fim, reforça-se que, de maneira geral, os resultados obtidos indicam que a escala se mostra confiável para ser utilizada em estudos que visem precisamente avaliar a motivação de estudantes em aulas de Física, ou seja, de estudantes que queiram saber com qual grau de regulação autônoma eles fazem as atividades didáticas nas aulas. Considera-se também que a escala é um instrumento importante para pesquisas que objetivem propor e avaliar novos recursos didáticos ou novas perspectivas didático-pedagógicas, pois com ela se poderá medir um eventual aumento na motivação dos estudantes, decorrente da utilização destes novos recursos, e/ou novas perspectivas de ensino.

\section{Referências}

Alsop, S. (Ed.). (2005). Beyond cartesian dualism: encountering affect in the teaching and learning of science. Dordrecht: Kluwer Academic Publishers.

Baram-Tsabari, A., \& Yarden, A. (2005). Characterizing children's spontaneous interests in science and technology. International Journal of Science Education, 27(7), 803-826.

Black, A. E., \& Deci, E. L. (2000). The effects of instructors autonomy support and students autonomous motivation on learning organic chemistry: a self-determination theory perspective. Science Education, 84, 740-756.

Boruchovitch E., \& Bzuneck, J. A. (2010). Motivação para aprender no Brasil: estado da arte e caminhos futuros. Em E. Boruchovitch, J. A. Bzuneck \& S. E. R. Guimarães (Orgs.), Motivação para Aprender: aplicações no contexto educativo (pp. 231-254). Petrópolis, RJ: Vozes.

Broc, M. A. (2006). Motivación y rendimiento académico en alumnos de educación secundaria obligatoria y bachillerato LOGSE. Revista de Educación, 340, 379-414.
Broc, M. A., \& Gil, C. (2008). Predicción del rendimiento académico en alumnos de ESO y Bachillerato mediante el inventario clínico para adolescentes de Millon (escala MACI). Anales de Psicología, 24(1), 158-167.

Buccheri, G., Gürber, N. A., \& Brühwiler, C. (2011). The impact of gender on interest in science topics and the choice of scientific and technical vocations. International Journal of Science Education, 33(1), 159-178.

Bybee, R., \& McCrae, B. (2011). Scientific literacy and student attitudes: perspectives from PISA 2006 science. International Journal of Science Education, 33(1), 7-26.

Bzuneck, J. A., \& Guimarães, S. E. R. (2010). A promoção da autonomia como estratégia motivacional na escola: uma análise teórica e empírica. Em E. Boruchovitch, J. A. Bzuneck \& S. E. R. Guimarães (Orgs.), Motivação para aprender: aplicações no contexto educativo (pp. 43-70). Petrópolis, RJ: Vozes.

Deci, E. L. (1971). Effects of externally mediated rewards on intrinsic motivation. Journal of Personality and Social Psychology, 18, 105-115.

Deci, E. L., \& Ryan, R. M. (1985). Intrinsic motivation and selfdetermination in human behavior. New York. Plenum Press.

Deci, E. L. e cols. (1981). An instrument to assess adults' orientation toward control versus autonomy with children: reflections on intrinsic motivation and perceived competence. Journal of Educational Psychology, 73, 642-650.

Deci, E. L., e cols. (1991). Motivation in education: the self-determination perspective. Educational Psychologist, 26(3/4), 325-346.

Gottfried, A. E., Fleming, J. M., \& Gottfried, A. W. (2001). Continuity of academic intrinsic motivation from childhood through late adolescence: a longitudinal study. Journal of Educational Psychology, 93(1), 3-13.

Guimarães, S. E. R., \& Bzuneck, J. A. (2008). Propriedades psicométricas de um instrumento para avaliação da motivação de universitários. Ciências \& Cognição, 13(1), 101-113.

Harter, S. (1981). A new self-report scale of intrinsic versus extrinsic orientation in the classroom: motivational and informational components. Developmental Psychology, 17(3), 300-312.

Kline, P. (1994). An easy guide to factor analysis. New York: Routledge.

Koh, J. H. L., \& Frick, T. W. (2010). Implementing autonomy support: insights from a montessori classroom. International Journal of Education, 2(2), 1-15.

Krapp, A., \& Prenzel, M. (2009). Research on interest in science: theories, methods, and findings. International Journal of Science Education, 33(1), 27-50. 
Lepper, M. R., Corpus, J. H., \& Iyengar, S. (2005). Intrinsic and extrinsic motivation in the classroom: age differences and academic correlates. Journal of Educational Psychology, 97(2), 184-196.

Martinelli, S. C., \& Bartholomeu, D. (2007). Escala de motivação acadêmica: uma medida de motivação extrínseca e intrínseca. Avaliação Psicológica, 6(1), 21-31.

Neves, E. R. C., \& Boruchovitch, E. (2006). Escala de avaliação para aprender de alunos do ensino fundamental (EMA). Psicologia: Reflexão e Crítica, 20(3), 406-413.

Niemiec, C. P., \& Ryan, R. M. (2009). Autonomy, competence, and relatedness in the classroom: applying self-determination theory to educational practice. Theory and Research in Education, 7(2), 133-144.

Park, H., Khan, S., \& Petrina, S. (2009). ICT in science education: a quasiexperimental study of achievement, attitudes toward science, and career aspirations of Korean middle school students. International Journal of Science Education, 31(8), 993-1012.

Pasquali, L. (1997). Psicometria: teoria e aplicações. Brasília: Ed. da Universidade de Brasília.

Reeve, J. (2006). Motivação e Emoção (A.F.L. Pontes \& S. Machado, Trad., 4a ed.). Rio de Janeiro: LTC.

Ricardo, E. C. (2010). Problematização e contextualização no ensino de física. Em A. M. P. Carvalho (Org.), Ensino de Física (pp. 2951). São Paulo: Cengage Learning.
Roth, G. e cols. (2007). Autonomous motivation for teaching: how selfdetermined teaching may lead to self-determined learning. Journal of Education Psychology, 99(4), 761-774.

Rufini, S. E., Bzuneck, J. A., \& Oliveira, K. L. (2011). Estudo de validação de uma medida de avaliação da motivação para alunos do ensino fundamental. Psico-USF, 16(1), 1-9.

Ryan, R. M., \& Deci, E. L. (2000a). Intrinsic and extrinsic motivations: classic definitions and new directions. Contemporary Educational Psychology, 25(1), 54-67.

Ryan, R. M., \& Deci, E. L. (2000b). Selfdetermination theory and the facilitation of intrinsic motivation, social development, and wellbeing. American Psychologist, 55(1), 68-78.

Silvia, P. J. (2006). Exploring the psychology of interest. New York: Oxford University Press.

Stefanou, C. R. e cols. (2004). Supporting autonomy in the classroom: ways teachers encourage student decision making and ownership. Educational Psychologist, 39, 97-110.

Tsai, Y. e cols. (2008). What makes lessons interesting? The role of situational and individual factores in three school subjects. Journal of Educational Psychology, 100(2), 460-472.

Vallerand, R. J. e cols. (1989). Construction et validation de l'échelle de motivation en éducation (EME). Canadian Journal of Behavioral Sciences, 21(3), 323-349. 


\section{Sobre os autores}

Luiz Clement (Iclement@joinville.udesc.br)

Mestre em Educação pela UFSM, Doutorando do PPGECT/UFSC e é Professor do Departamento de Física da Universidade do Estado de Santa Catarina, Joinville, Brasil.

José Francisco Custódio (custodio@fsc.ufsc.br)

Doutor em Educação Científica e Tecnológica pela UFSC e é Professor do Departamento de Física e do Programa de Pós-Graduação em Educação Científica e Tecnológica da Universidade Federal de Santa Catarina, Florianópolis, Brasil.

Sueli Édi Rufini (sueli.rufini@pesquisador.cnpq.br)

Doutora em Educação pela UNICAMP e é Professora do Departamento de Educação e do Programa de Pós Graduação em Educação da Universidade Estadual de Londrina, Londrina, Brasil.

José de Pinho Alves Filho (jopinho@fsc.ufsc.br)

Doutor em Educação: Ensino de Ciências Naturais pela UFSC e é Professor do Departamento de Física e do Programa de Pós-Graduação em Educação Científica e Tecnológica da Universidade Federal de Santa Catarina, Florianópolis, Brasil. 